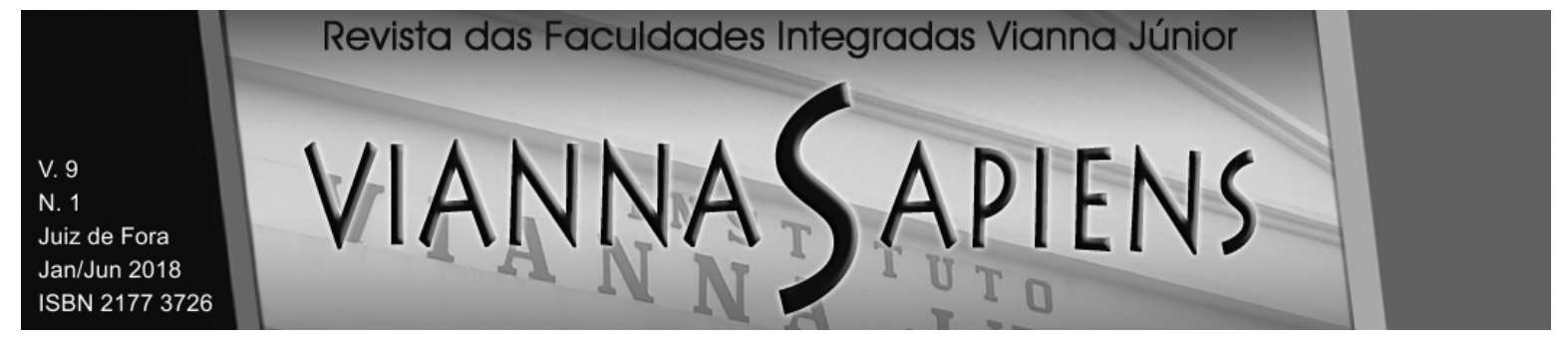

\title{
A REFORMA TRABALHISTA E A REGULAMENTAÇÃO DO TELETRABALHO
}

DOI: $10.31994 /$ rvs.v9i1.349

Fernanda Maria dos Reis ${ }^{1}$

\section{RESUMO}

O presente trabalho tem como escopo analisar a disciplina do teletrabalho, recentemente regulamentado em nosso ordenamento jurídico pela Reforma Trabalhista, a Lei 13.467/2017. Para tanto, o método utilizado foi a pesquisa bibliográfica sobre o tema, ao amparo da doutrina, da legislação e da análise jurisprudencial. As principais conclusões foram de que a nova modalidade contratual foi regulamentada de maneira bastante lacunosa, mas ainda assim, de maneira bastante providencial, haja vista a crescente utilização dessa modalidade de trabalho. Concluiu-se ainda, pela necessidade de compatibilização da disciplina do teletrabalho com as normas constitucionais e de direito do trabalho em vigor em nosso ordenamento, sob pena de precarização do trabalho. Caso assim procedam os operadores do Direito, a disciplina do teletrabalho, pela reforma trabalhista, não será capaz de trazer maiores prejuízos ao trabalhador que preste serviços se valendo da telemática.

PALAVRAS CHAVES: REFORMA TRABALHISTA. TRABALHO À DISTÂNCIA. TELETRABALHO. DIREITO DO TRABALHO. REGULAMENTAÇÃO.

\footnotetext{
${ }^{1}$ Advogada, Especialista em Direito Empresarial e Econômico pela UFJF, Professora das Faculdades Integradas Vianna Júnior, https://orcid.org/0000-0002-0469-480X
} 


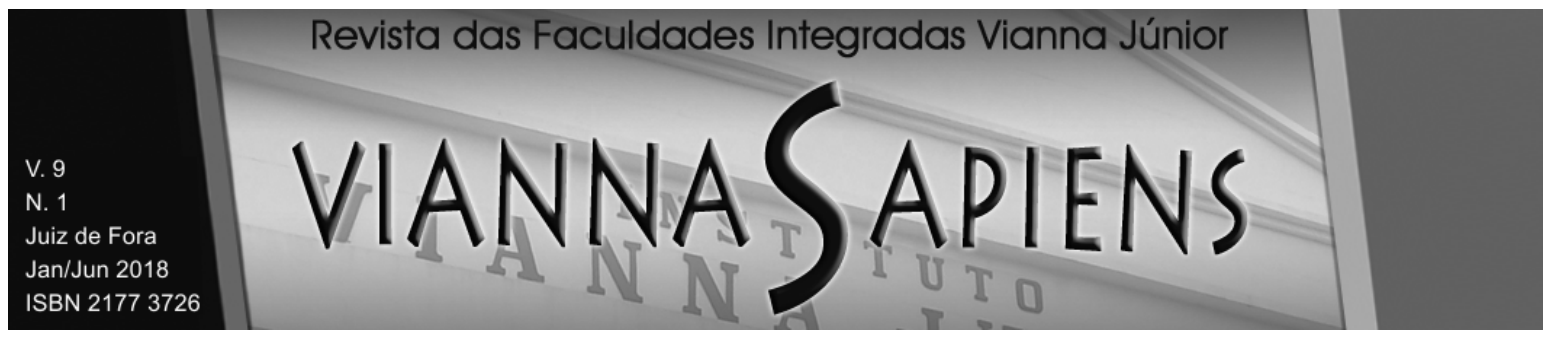

INTRODUÇÃO

O rápido avanço da tecnologia vem causando forte impacto nas relações sociais e, por via de consequência, trazendo implicações que não podem ser ignoradas pelo Direito.

Assim, como acontece com um sem número de relações jurídicas, as relações laborais estão sendo profundamente afetadas pelo uso da tecnologia, em especial, mas não apenas, pelo computador e pela internet.

A nova realidade traz consigo pontos positivos e negativos. A título de exemplo, podemos citar a prestação de serviços com maior comodidade para o trabalhador, o incremento da produção, o aperfeiçoamento das ferramentas de controle e o quão frequente se tornou o ajuizamento de reclamações trabalhistas discutindo a pertinência da dispensa por justa causa, motivada pelo uso indevido do aparelho celular em local e horário de trabalho.

O emprego da tecnologia impacta o Direito Laboral, também ao tornar possível e mais frequente a utilização do teletrabalho, espécie de trabalho prestado a distância e que apresenta múltiplas vantagens, dentre elas: a flexibilidade de horário para o trabalhador; a eliminação do tempo perdido no trânsito; a redução do espaço utilizado pela planta empresarial e a redução dos custos com transporte pelo empregador.

Entretanto, o teletrabalho apresenta também sua face nociva, em especial, para o empregado, que perde o contato com outros trabalhadores; que vê reduzida a chance de ascensão dentro da empresa e, que, muitas vezes, não consegue respeitar seus períodos de descanso pela dificuldade de separar a vida profissional da vida pessoal.

A Lei n. 13.467/2017, popularmente conhecida como Reforma Trabalhista, implicou em substancial alteração do Direito do Trabalho no Brasil e, ao fazê-lo, ocupou-se, pela primeira vez, da regulação do trabalho humano empregado por meio da telemática, o teletrabalho, já presente no Brasil há aproximadamente trinta anos, mas até então, com disciplina legal praticamente inexistente. 


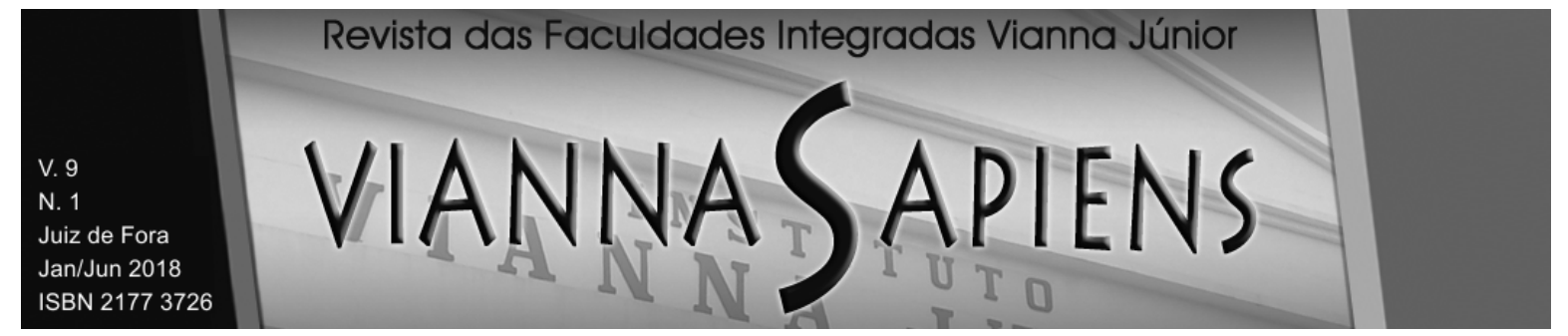

Para tanto, o legislador reformista, inspirado pelo Código do Trabalho português, inseriu no texto celetista o capítulo II-A, composto pelos artigos 75-A a $75-\mathrm{E}$, bem como o art. 62, III, que agora se somam ao parágrafo único do artigo $6^{\circ}$ consolidado, o dispositivo legal que até então se ocupava da matéria.

Tratando-se de modalidade contratual recentemente regulamentada e considerando que apesar do avanço representado pela regulamentação da matéria, o legislador em vários momentos não se valeu da melhor técnica, o presente trabalho tem como objetivo analisar a disciplina do teletrabalho, recentemente regulamentado em nosso ordenamento jurídico pela Reforma Trabalhista, a Lei $13.467 / 2017$.

A fim de alcançar o mencionado objetivo, este trabalho foi realizado a partir da pesquisa bibliográfica com base na doutrina, na legislação e também na jurisprudência.

Para tanto, inicialmente, diferenciou-se, o trabalho prestado por meio da telemática do trabalho em domicílio e, ainda, do trabalho externo. Em seguida, foram analisados os artigos pertinentes ao tema, recém introduzidos no texto celetista pelo legislador reformista, a saber: o contrato de trabalho; a alteração do regime de trabalho; a responsabilidade pela aquisição dos equipamentos tecnológicos e da infraestrutura necessária e adequada à prestação do trabalho; as medidas de proteção e saúde do teletrabalhador e, por fim, a exclusão do teletrabalhador das regras de jornada de trabalho trazidas pela CLT.

\section{OS TRABALHADORES A DISTÂNCIA E A CARACTERIZAÇÃO DO TELETRABALHO}

O trabalho prestado a distância, fora da sede do empregador não é algo novo e comporta duas modalidades, a saber: o empregado em domicílio e o teletrabalhador. 


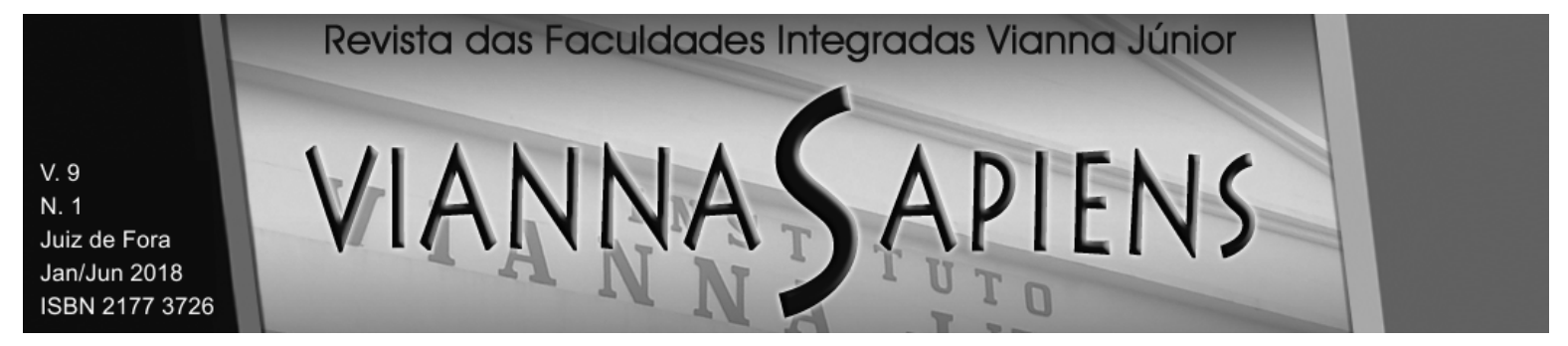

O trabalho em domicílio, figura bastante antiga surge na Europa, no início do século XVI, sendo definido pela CLT, em seu art. 83, como o prestado "na habitação do empregado ou em oficina de família, por conta de empregador que o remunere", está relacionado ao trabalho manual. Neste sentido, as costureiras são exemplo citado de maneira recorrente pela doutrina.

Com o passar dos anos o trabalho prestado "fora das vistas" do empregador foi adquirindo novos contornos e hoje não se relaciona unicamente àquele trabalho manual. É cada vez mais comum o trabalho prestado fora das dependências da empresa, envolvendo tarefas mais complexas e por meio de métodos telemáticos, com o emprego de ferramentas de telecomunicações e de informática. É o chamado teletrabalho.

Segundo Renzetti (2017, p. 136):

No teletrabalho, o trabalhador tem a possibilidade de executar os serviços fora do estabelecimento do empregador, e necessita conectar-se a meios de comunicação telemáticos ou informatizados. O referido trabalho só se torna possível graças ao auxílio da internet, que é um instrumento absolutamente inserido no contexto social:

E continua o mesmo autor:

A grande evolução ocorrida em razão do surgimento dessa nova modalidade foi capaz de modificar a maneira como se executa o trabalho e, ainda, a disposição de espaço e tempo durante a prestação de serviços.

Bramante (2012, p.402), propõe uma definição para teletrabalho nos seguintes termos: "teletrabalho é a prestação de serviços, a qualquer título, descentrada e ou externalizada, mediante a utilização dos instrumentos da telemática".

Com a reforma trabalhista o teletrabalho ganhou definição legal. Conforme a redação do novo art. 75-B da CLT: 


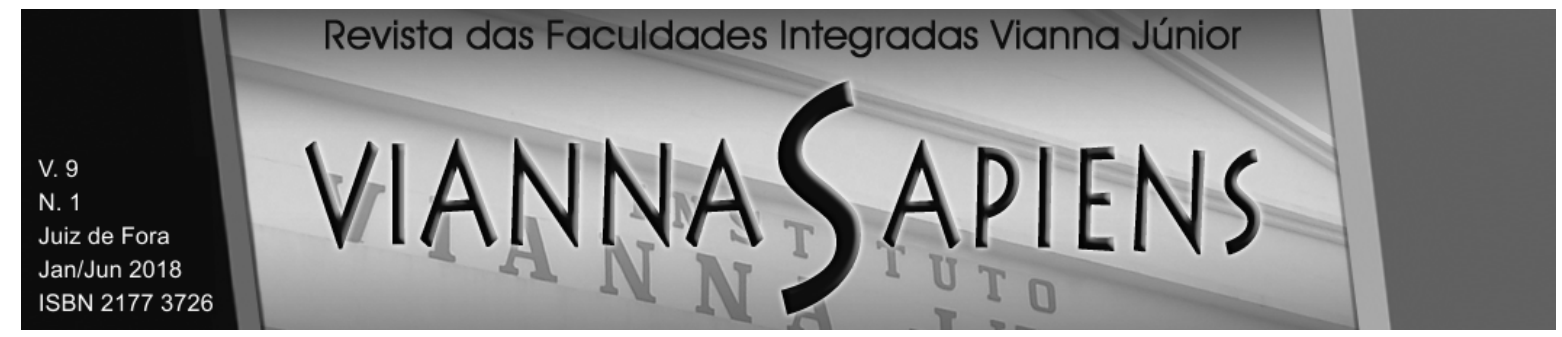

Considera-se teletrabalho a prestação de serviços preponderantemente fora das dependências do empregador, com a utilização de tecnologias de informação e de comunicação que, por sua natureza, não se constituam como trabalho externo.

Da leitura do dispositivo retro extraem-se as seguintes características:

O teletrabalho é prestado preponderantemente a distância, não é prestado na sede do empregador. Contudo, o comparecimento a sede para a realização de atividades específicas não o descaracteriza, desde que tais comparecimentos não sejam excessivos; Além disso, o trabalho deve ser prestado com o uso de tecnologias da informação e da comunicação, por exemplo, internet e aplicativos, tais como e-mail, Whatsapp.

O teletrabalhador pode desempenhar suas atividades em sua residência, em centros específicos para esta finalidade, numa cafeteria, em uma lan house, mas sempre em local fixo, no que se diferencia do trabalhador externo que desempenha suas atividades em vários locais e do qual podemos citar como exemplos, o vendedor externo e o ajudante de viagem, profissionais que não possuem um local fixo para o desempenho de sua atividade laboral.

O fato de o trabalho ser prestado a distância, não afasta, por si só, a condição de empregado, embora os requisitos da relação de emprego possam ser de mais difícil aferição, em especial, a subordinação e a pessoalidade. Neste sentido já previa o parágrafo único do $\operatorname{art}^{\circ}$ da CLT ao equiparar os meios telemáticos e informatizados de comando, controle e supervisão aos meios pessoais e diretos de comando, controle e supervisão do trabalho alheio, para fins de subordinação jurídica.

Referido parágrafo é um desdobramento da regra trazido pelo caput do mesmo artigo, segundo o qual, não se distingue entre o trabalho realizado no estabelecimento do empregador, o executado no domicílio do empregado e o realizado a distância, desde que estejam caracterizados os pressupostos da relação de emprego". 


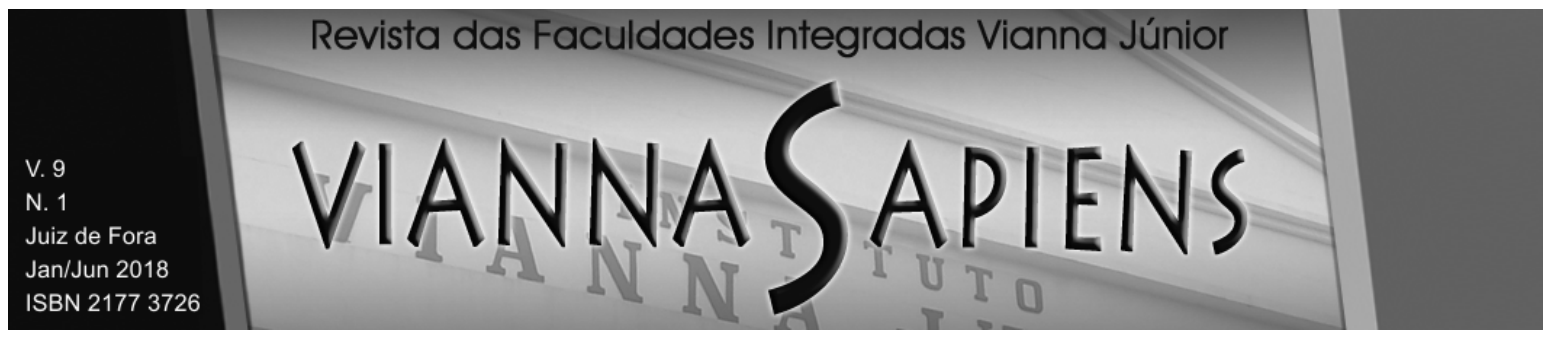

\section{DA REGULAMENTAÇÃO DO TELETRABALHO}

\subsection{Do Contrato de Trabalho}

Exige o art. 75-C da Consolidação das Leis do Trabalho, alguma formalidade com relação a adoção do Teletrabalho. Segundo o dispositivo legal, do contrato individual de trabalho deve constar expressamente a prestação de serviços na modalidade de teletrabalho. Além de serem indicadas as atividades que serão realizadas pelo trabalhador.

Assim, por força de expressa previsão legal, não incide a regra geral do art. 443 da CLT, que permite a celebração do contrato de trabalho, tácita ou expressamente, verbalmente ou por escrito. Em se tratando de contrato de trabalho envolvendo a figura do teletrabalho, portanto, contrato especial, o instrumento contratual deve ser, necessariamente, escrito. Além de conter as atividades que serão desenvolvidas pelo empregado.

Por certo, a inobservância do contrato escrito, afasta a condição do teletrabalho, o que traz implicações como, a aplicação do capítulo celetista da jornada de trabalho ao empregado. Neste sentido, Nascimento (2005) não admite a celebração oral dos contratos de trabalho com cláusula especial, invocando para tanto, o art. 29 da CLT.

\subsection{Da Alteração do Regime de Trabalho}

O texto Celetista, ao regulamentar o teletrabalho prevê a hipótese de alteração do regime de trabalho presencial para o regime de teletrabalho e viceversa. Neste sentido, é imperioso pontuar que em ambas as situações (teletrabalho para presencial e presencial para teletrabalho), deve ser providenciado um aditivo contratual.

Além disso, a alteração do regime presencial para o teletrabalho exige mútuo acordo, significa dizer, não pode ser imposta unilateralmente pelo empregador. Em 


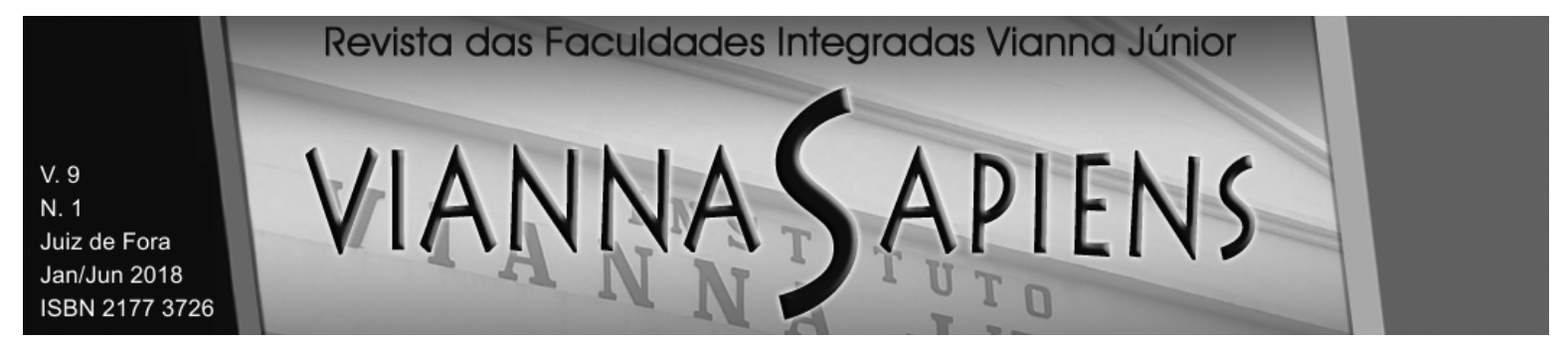

sentido contrário, a alteração do regime de teletrabalho para o presencial pode ser determinada unilateralmente pelo empregador. Ao que parece, o legislador incluiu dita alteração dentro do jus variandi do empregador.

Entretanto, sabe-se que o Direito do Trabalho é regido por princípios próprios e que lhe são bastante caros. Assim, é preciso levar em consideração o princípio da inalterabilidade contratual lesiva, materializado no art. 468 da CLT, pelo qual:

Nos contratos individuais de trabalho só é lícita a alteração das respectivas condições por mútuo consentimento, e ainda assim desde que não resultem, direta ou indiretamente, prejuízos ao empregado, sob pena de nulidade da cláusula infringente desta garantia.

Deste modo, sendo a alteração do regime de teletrabalho para o presencial, ou vice-versa, prejudicial para o empregado, a mesma não deve ser admitida.

De todo modo, para que o teletrabalhador venha a prestar seus serviços dentro do estabelecimento empresarial, por imposição do empregador, deve ser concedido ao mesmo um prazo de transição mínimo, de 15 dias.

Segundo Paula (2018, p.220):

A redação dos dispositivos aponta inicialmente para dois problemas: não há necessidade de justificar os motivos da transição mutuamente acordada entre as partes, tratada no parágrafo primeiro, tampouco da transição determinada pelo empregador no parágrafo segundo. Ademais, também não há previsão de penalidade na hipótese de descumprimento do prazo mínimo de 15 dias para a adaptação da transição determinada pelo empregador.

A desigual situação entre trabalhador e empregador, por si, já descaracteriza o pretenso 'mútuo acordo' na transição entre as modalidades de teletrabalho e presencial, daí concluir-se que dificilmente o trabalhador recusará a proposta de transição feita pelo empregador, já que corre o risco de perder o emprego. Da mesma forma, não tem o trabalhador nenhuma garantia de cumprimento do prazo mínimo para retorno do teletrabalho ao presencial, o que se revela necessário em razão de possíveis adaptações a serem feitas em sua vida pessoal, além do planejamento do deslocamento, 


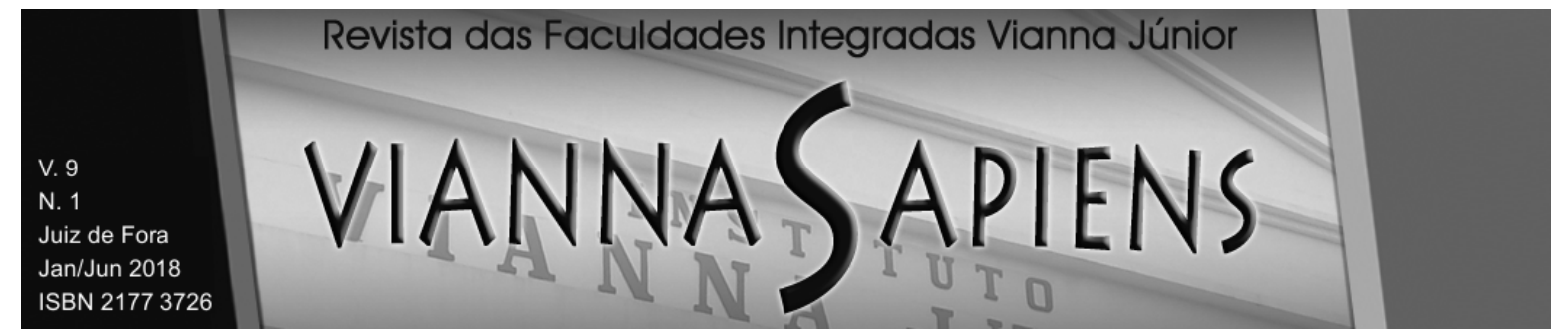

situação que pode até mesmo permitir a aplicação analógica do artigo 469 da CLT.

Como se nota, o legislador não andou bem ao disciplinar a alteração do regime de trabalho.

\subsection{Dos Equipamentos Tecnológicos e da Infraestrutura Necessária e Adequada à Prestação do Trabalho}

O recém inserido art.75 - D vem sendo alvo de incontáveis críticas ao dispor que:

As disposições relativas à responsabilidade pela aquisição, manutenção ou fornecimento dos equipamentos tecnológicos e da infraestrutura necessária e adequada à prestação do trabalho remoto, bem como ao reembolso de despesas arcadas pelo empregado, serão previstas em contrato escrito.

É que para muitos doutrinadores a previsão de que a responsabilidade pela aquisição e manutenção de equipamentos e infraestrutura, será prevista em instrumento contratual, sabidamente um contrato de adesão, seria um permissivo para que o empregador atribuísse dita responsabilidade ao empregado.

Para Cassar (2018, p.275): “o teletrabalhador, dependendo do ajuste, poderá arcar com os custos da aquisição, manutenção dos equipamentos tecnológicos e infraestrutura do trabalho (art. 75-D da CLT)".

De fato, a redação do artigo não é das mais felizes, o que aliás, acontece com bastante frequência na Lei 13.467/2017. Não obstante, entendimento nesse sentido encontra óbice na redação do art. $2^{\circ}$ da CLT, pelo qual o empregador assume os riscos da atividade econômica que desempenha, não podendo atribuir tais encargos aos trabalhador, havendo que se prestigiar o princípio da alteridade.

A seu respeito leciona Cassar (2018, p. 272): 


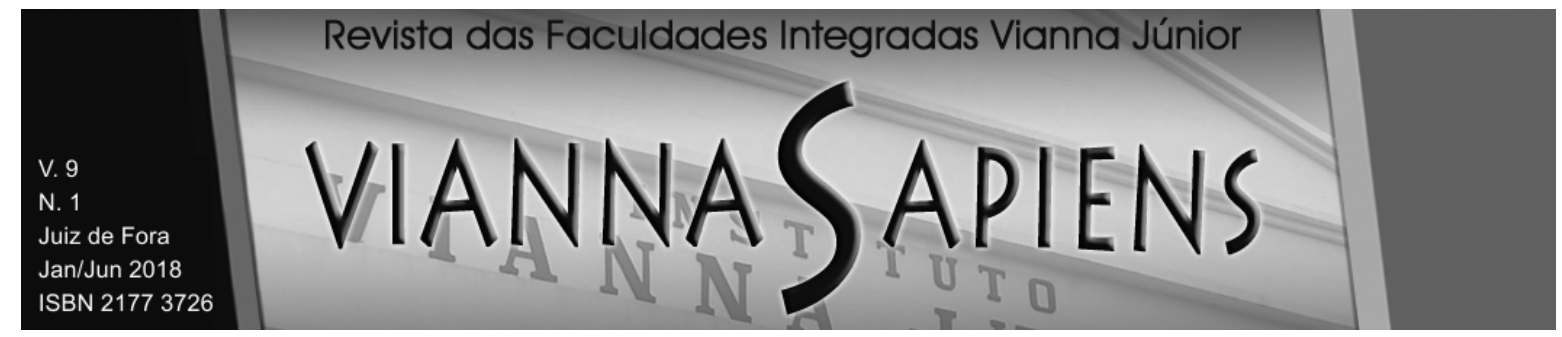

Um empreendimento para ter sucesso depende de muitos fatores além de sorte, e quem corre o risco do negócio é sempre o empregador. Este é um critério diferenciador, já que todos os outros requisitos podem estar presentes, em maior ou menor intensidade, mas se o trabalhador correr o risco do negócio, empregado não será.

Outro ponto que deve ser destacado é que o dispositivo faz referência expressa "ao reembolso das despesas arcadas pelo empregado". Deste modo, o custeio pelo empregador é certo, de forma que, o que poderia ser objeto de previsão contratual, seriam aspectos, tais como, a responsabilidade pela aquisição do mobiliário, pela contratação da internet, o prazo e forma de reembolso.

Arcando o empregador com a aquisição, manutenção ou o fornecimento dos equipamentos tecnológicos e da infraestrutura necessária e adequada à prestação do trabalho remoto, os instrumentos utilizados a ele pertencem, não sendo lícito ao empregado deles livremente dispor, ou mesmo ignorar as regras de utilização impostas pelo empregador.

Situação que exige solução diversa, é aquela em que ocorre a possibilidade de uso das ferramentas de trabalho também para fins particulares, hipótese em que a jurisprudência há muito admite que as despesas sejam divididas entre a empresa e o empregado. Como exemplo, as despesas com internet que, a princípio pode ser utilizada livremente pelo empregado para fins particulares/pessoais, sem qualquer limitação de acesso ou controle por parte do empregador. No caso na nada mais justo que a despesa seja compartilhada.

Buscando afastar qualquer celeuma quanto a natureza das utilidades necessárias e fornecidas para o desempenho da atividade o parágrafo único do mesmo art. 75-D afirma expressamente que as utilidades não fazem parte da remuneração: "Parágrafo único. As utilidades mencionadas no caput deste artigo não integram a remuneração do empregado." E não poderia ser diferente, pois se tratam de utilidades fornecidas para a prestação dos serviços.

\subsection{Das Medidas de Proteção e Saúde do Teletrabalhador}

Nos termos do art. 75-E da CLT, com redação dada pela reforma trabalhista: 


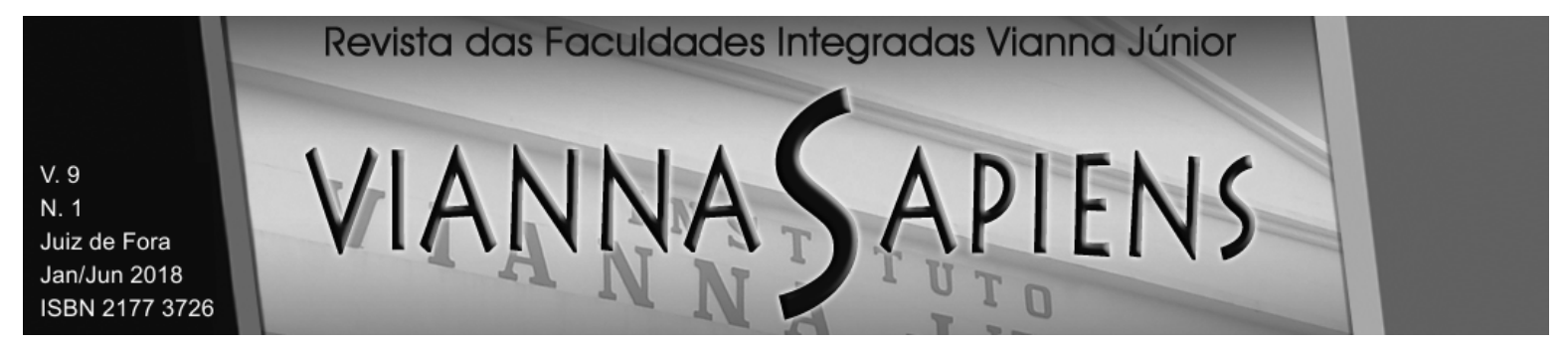

O empregador deverá instruir os empregados, de maneira expressa e ostensiva, quanto às precauções a tomar a fim de evitar doenças e acidentes de trabalho.

Parágrafo único. O empregado deverá assinar termo de responsabilidade comprometendo-se a seguir as instruções fornecidas pelo empregador.

Estamos aqui diante de mais uma previsão controvertida, alvo de acaloradas críticas. Argumenta-se que o legislador buscou isentar empregador de responsabilidade com relação a saúde e segurança do empregado, desde que haja instruído o teletrabalhador.

Por certo, a previsão supra, por si só, não afasta a possibilidade de responsabilização do empregador pela infortunística laboral, embora seja inconteste que o empregado que telelabora encontrará maior dificuldade para a comprovação do nexo causal, bem como da culpa do empregador.

A este respeito o direito comparado é grande importância. Conforme esclarece Barros (2017, p.217):

Os tribunais espanhóis, por exemplo, quando definem pela relação empregatícia do teletrabalhador, realçam que as novas tecnologias não poderão servir de burla à legislação vigente e assimilam a presença física virtual, destacando que o empregador recebe por meio da internet a mesma prestação de serviços que receberia se o empregado estivesse na empresa, sendo idêntico o resultado do trabalho para as partes. Concluem que o avanço tecnológico não poderá implicar retrocesso social, favorecendo a precariedade do emprego.

Por certo, a prestação de serviços fora do estabelecimento empresarial, não afasta a responsabilidade do empregador com relação ao cumprimento das normas de higiene e segurança do trabalho e, nem mesmo, a possibilidade de sua responsabilização diante da ocorrência do acidente do trabalho e da doença profissional. Neste sentido teve oportunidade de decidir o Tribunal Regional do Trabalho da $3^{\circ}$ Região:

EMENTA: INDENIZAÇÃO POR DANOS MORAIS. DOENÇA PROFISSIONAL. CULPA DO EMPREGADOR. EMPREGADO EM 


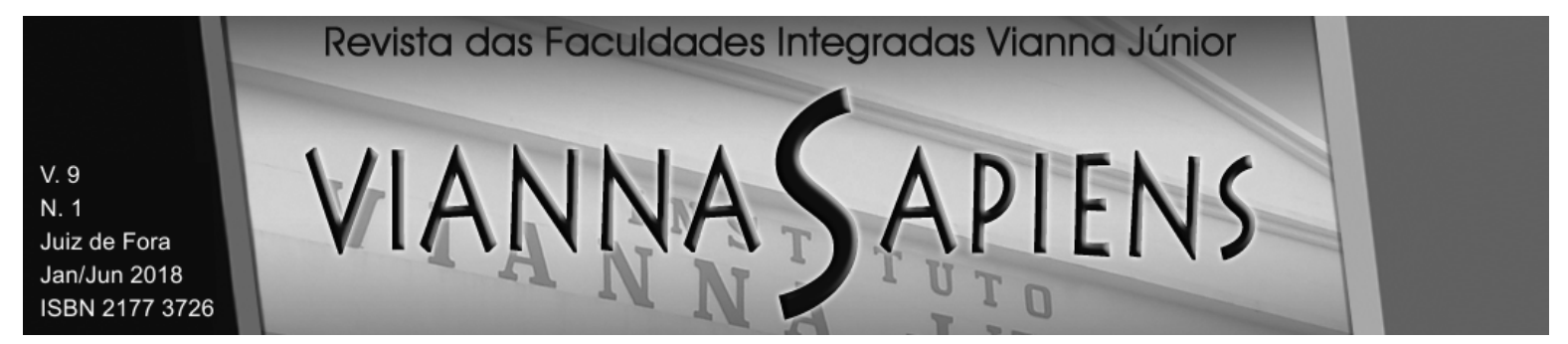

DOMICÍLIO. O fato de o empregado trabalhar em domicílio não constitui, por si só, motivo para eximir o empregador da observância das normas de segurança e medicina do trabalho, colocando o trabalhador à margem da proteção legal que deve abranger "todos os locais de trabalho", sem distinção (artigo 154 da CLT). É certo que não há como exigir do empregador, em semelhante circunstância, a fiscalização cotidiana dos serviços prestados, inclusive quanto à efetiva observância pelo empregado das normas de segurança e medicina, mesmo porque a casa é asilo inviolável do indivíduo, ninguém nela podendo penetrar sem o consentimento do morador, salvo em caso de flagrante delito ou desastre, ou para prestar socorro, ou, durante o dia, por determinação judicial, nos termos da garantia estatuída no artigo 5o., inciso XI, da Constituição Federal. Essa particularidade, sem dúvida, constitui elemento que vai interferir na gradação da culpa do empregador em relação a eventual doença profissional constatada, mas não permite isentá-lo do cumprimento de obrigações mínimas, como a de instruir os empregados quanto às precauções a tomar no sentido de evitar acidentes do trabalho ou doenças ocupacionais, nos termos do artigo 157, II, da CLT, além de fornecer mobiliário adequado, orientando o empregado quanto à postura correta (artigo 199 da CLT), pausas para descanso, etc. Verificado o descumprimento dessas obrigações primordiais pelo empregador, em face da sua omissão negligente no tocante aos cuidados com a saúde da empregada, é inegável a sua culpa no surgimento da doença profissional constatada, incidindo sua responsabilidade pela compensação do dano moral sofrido pela obreira.

Importante esclarecer que a assinatura do termo de responsabilidade, previsto no parágrafo único, pelo trabalhador não afasta a obrigação de indenizar do empregador, caso tenha atuado com culpa ou dolo.

\subsection{Da Exclusão das Regras de Jornada de Trabalho Trazidas pela CLT}

A Lei 13.467/2017 acresceu o inciso III ao artigo 62 do texto Celetista, excluindo, dessa forma, o teletrabalhador, da disciplina da jornada de trabalho contida na própria CLT. Deste modo, o teletrabalhador não teria direito ao pagamento de horas extras, de adicional noturno, de adicional de sobreaviso/prontidão, intervalo intrajornada, dentre outros.

É preciso considerar que (Delgado, 2017, p.138): 


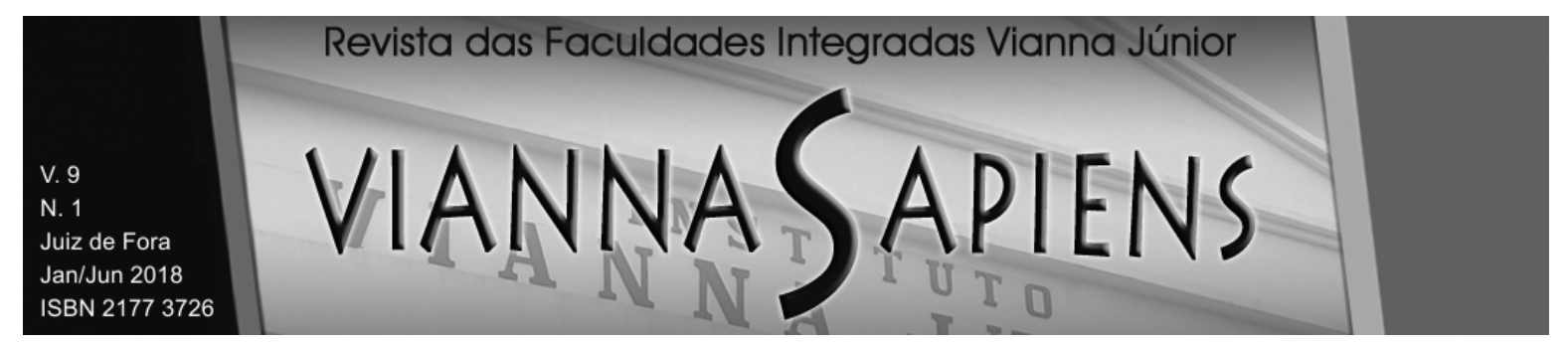

De fato, em várias situações de teletrabalho mostra-se difícil enxergar controle estrito da duração do trabalho, em face da ampla liberdade que o empregado ostenta, longe das vistas de seu empregador, quanto à escolha dos melhores horários para cumprir os seus misteres provenientes do contrato empregatício.

Contudo, a inserção do trabalhador que se vale da telemática para a prestação dos seus serviços, dentre as exceções trazidas pelo dispositivo mencionado, tem sido bastante criticada por alguns doutrinadores, que se posicionam a respeito considerando a previsão legal como absoluta.

Não obstante, com todo respeito que merecem aqueles que assim entendem, esse não é o melhor entendimento a respeito da nova previsão legal. É que dita previsão deve ser compreendida como presunção relativa, pois o art. 62 parte do princípio de que os empregados nele previstos não têm jornada de trabalho fiscalizada, de que são livres para escolherem o horário e por quanto tempo trabalham.

Não obstante, em que pese se encontre o trabalhador em regime de teletrabalho, inicialmente, afastado das regras celetistas sobre jornada, se o empregador, por qualquer meio, realizar o controle do tempo de labor, a regra do art. 62, III, não deve surtir qualquer efeito. Interpretação em sentido contrário implica afronta ao artigo $7^{\circ}$, incisos XIII e XVI da Constituição da República.

A solução que deve ser dada é a mesma que se aplica ao trabalhador externo, hipótese em que, o fato de o empregado realizar trabalho externo não significa dizer que o empregado não possua jornada controlada. Se for possível controlar os horários de início e término do trabalho, mesmo que o empregado exerça atividade externa, a ele será aplicada a jornada normal de trabalho, devendo Ihe ser assegurado o pagamento e eventuais horas extras, por exemplo.

Em igual sentido a lição de (Melo, 2017):

Assim, para se atribuir uma interpretação conforme à Constituição, de modo a compatibilizar os dispositivos da CLT, o inciso III do art. 62 deve ser compreendido como: encontram-se excluídos da proteção da jornada os teletrabalhadores que não possuem nenhuma forma de controle do tempo de trabalho. Isto é, aqueles empregados 


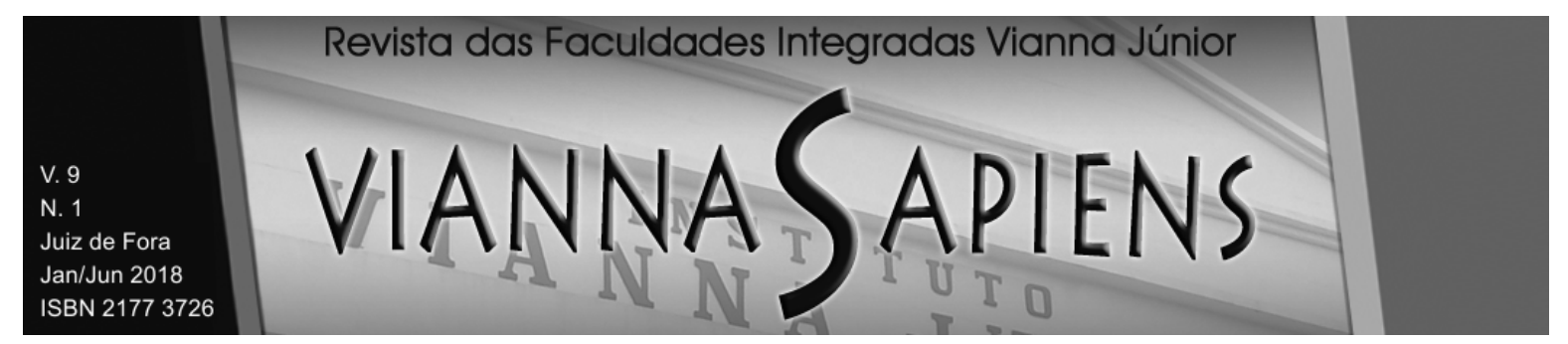

que iniciam e terminam suas atividades no horário que bem entenderem, com total liberdade. A cobrança patronal é feita por meio de metas e resultados, sem acompanhar os momentos em que a atividade está efetivamente sendo desempenhada.

Os teletrabalhadores que sofrerem vigilância dos períodos de conexão, controle de login e logout, localização física, pausas ou ligações ininterruptas para saber o andamento dos trabalhos, especialmente se de forma periódica, estão enquadrados na disposição do art. $7^{\circ}$ da CF/88 e no art. $6^{\circ}$, parágrafo único da CLT e possuem direito à proteção da jornada, inclusive eventuais horas extras.

Se assim considerarmos, serão raras as hipóteses em que o teletrabalhador não será beneficiado pelo capítulo referente à jornada de trabalho trazido pela CLT. É que pela própria natureza do teletrabalho, que nos termos legais, deve ser prestado com a utilização de tecnologias de informação e de comunicação, já de pronto se visualiza que o empregador terá melhores e maiores condições para controlar a jornada de trabalho do empregado, uma vez que tecnologia permite, inclusive, o monitoramento do tempo trabalhado e da produtividade, em tempo real.

Neste sentido, Cassar (2017, p.35) afirma:

O teletrabalhador pode ser facilmente monitorado por web camera, intranet, telefone, rádio, GPS, número mínimo de tarefas diárias etc. Aliás, o parágrafo único do art. $6 .^{\circ}$ da CLT é claro no sentido de que 'Os meios telemáticos e informatizados de comando, controle e supervisão se equiparam, para fins de subordinação jurídica, aos meios pessoais e diretos de comando, controle e supervisão do trabalho alheio'.

Importante salientar que, como a regra contida no inciso III do art. 62 da CLT é maléfica ao trabalhador, sua interpretação deve ser restritiva. Isso quer dizer que é requisito essencial para validade da exclusão do teletrabalhador ao Capítulo "Da Duração do Trabalho" a cláusula expressa em contrato escrito que indique essa modalidade de trabalho e especifique as tarefas que o empregado deve realizar.

Também Barros (2017, p. 218):

É possível, entretanto, aplicar ao teletrabalhador as normas sobre jornada de trabalho, quando estiver em conexão permanente com a empresa que lhe controla a atividade e o tempo de trabalho mediante a utilização de um programa informático capaz de armazenar na 


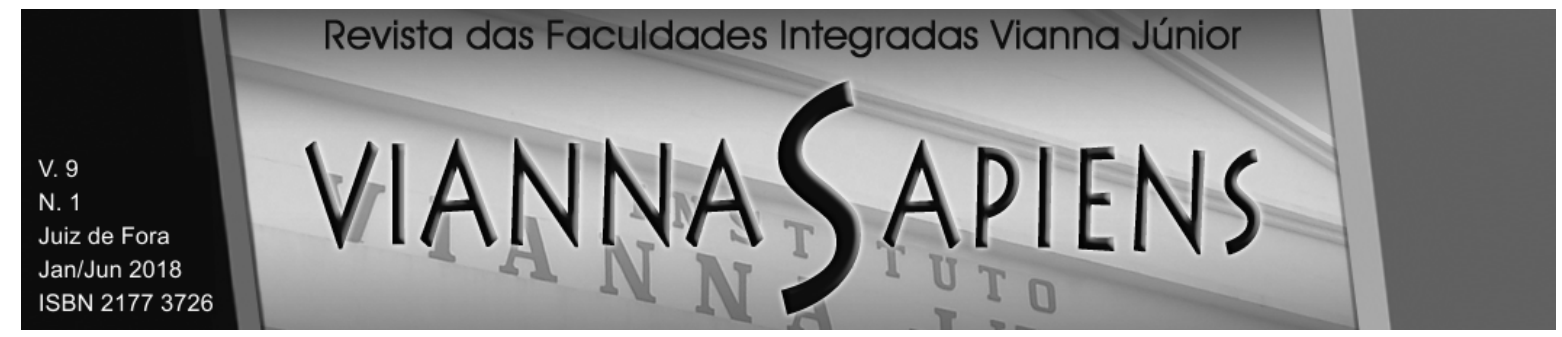

memória a duração real da atividade, dos intervalos, ou o horário definido pela exigência dos clientes do empregador, sem que o teletrabalhador tenha liberdade para escolher as horas que pretende trabalhar ao dia. Não há incompatibilidade entre o teletrabalho e a jornada extraordinária e, consequentemente, é possível também fixar o salário por unidade de tempo.

Não obstante, o ônus da prova quanto ao efetivo controle da jornada cabe ao empregado, pois a presunção aqui, atua em prol do empregador.

\section{CONCLUSÃO}

Uma das maiores críticas que se faz a reforma trabalhista é a insegurança jurídica que a mesma trouxe às relações de trabalho, justamente o contrário daquilo que se espera de um texto legal.

Especificamente com relação à disciplina do Teletrabalho a mesma foi bastante lacunosa, sendo que a doutrina vem apresentando posições contraditórias com relação a interpretação e aplicação dos poucos dispositivos destinados à matéria. Entretanto, ainda assim, a regulamentação foi providencial, sobretudo, quando se considera que o rápido avanço da tecnologia tem contribuído para o aumento das possibilidades da prestação de serviços fora do estabelecimento empresarial, em regime de teletrabalho. Essa é uma realidade que não tem volta, uma vez que, o telelabor, tende a se expandir cada vez mais.

Num primeiro momento, após uma interpretação meramente gramatical, percebe-se que as disposições trazidas pela reforma no tocante ao teletrabalho, buscam isentar ou reduzir as responsabilidades e ônus que naturalmente cabem ao empregador no âmbito das relações de emprego. Não obstante, os dispositivos legais não podem ser apreciados e aplicados isoladamente, devem ser compatibilizados com a ordem constitucional, com princípios gerais do direito, tais como, a boa-fé, e, também com o próprio direito do trabalho, com suas normas e princípios próprios, em especial, inalterabilidade contratual lesiva, alteridade, 


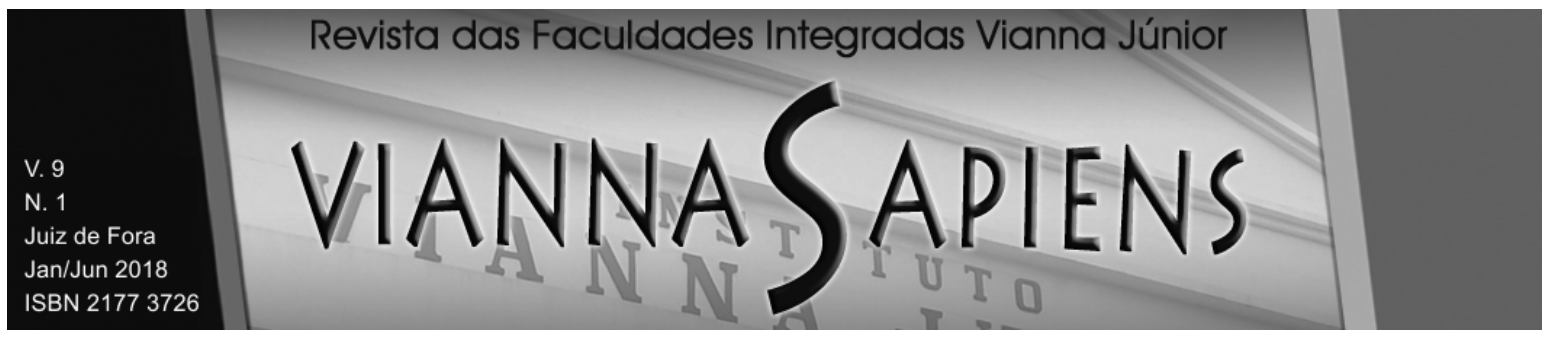

primazia da realidade, dentre outros, sob pena de admitir-se a precarização do trabalho, em especial, daquele relacionado ao teletrabalhador.

Conclui-se assim, que apesar das severas críticas, a disciplina do teletrabalho pela reforma trabalhista não se mostra apta a trazer maiores prejuízos ao trabalhador que preste serviços se valendo para tanto da telemática. Tal somente acontecerá se aplicador do Direito ignorar todo o regramento de proteção do trabalhador e assim permitir.

\section{LABOR REFORM AND REGULATION OF TELECOMMUTING}

\section{ABSTRACT}

The present work has scope of telework revision, recently regulated in the Labor Reform, a Law 13467/2017. The bibliographical research on the subject, under the protection of the doctrine, the legislation and the jurisprudential analysis. As the new contractual rules have been regulated in a very short time, but still, in a very providential way, it has an increasing vision of this modality of work. It was also concluded that the discipline of teleworking is compatible with the constitutional and labor law rules in force in its regulations, under penalty of precarious work. If he is not able to go to the teleworking service, the labor reform is not capable of posing greater risks to the worker who provides telematics evaluation services.

KEYWORDS: LABOR REFORM. TELECOMMUTING. REMOTE WORKING. LABOR LAW. REGULATION. 


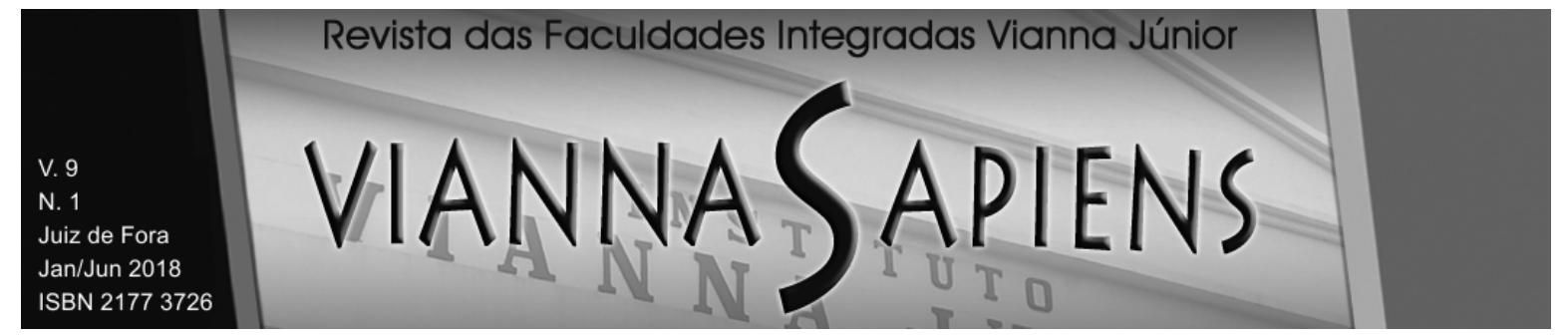

\section{REFERÊNCIAS}

AIDAR, L; RENZETTI, R; LUCA, G de. (orgs.). Reforma Trabalhista e reflexos no direito e processo do trabalho. São Paulo: LTr, 2017.

BARROS, Alice Monteiro de. Curso de direito do trabalho. 11. ed. São Paulo: LTr, 2017.

BRAMANTE, Ivani Contini. Teletrabalho - teledireção, telessubordinação e teledisposição. Revista LTr. São Paulo, SP, v. 76, n. 4, ex. 1, abr/2012, p. 396.

BRASIL. Consolidação das leis do trabalho (1943). Consolidação das leis do trabalho. Disponível: <http://www.planalto.gov.br/ccivil_03/decreto-lei/Del5452.htm>. Acesso em 20 de abr. 2018.

. Constituição (1988). Constituição da República Federativa do Brasil. Disponível: < >. Acesso em 20 de abr. 2018.

. Tribunal Regional do Trabalho da $3^{\circ}$ Região. Disponível:

https://portal.trt3.jus.br/internet/conheca-o-trt/comunicacao/noticiasjuridicas/importadas-faltantes/nj-especial-teletrabalho-como-a-jt-mineira-tem-seposicionado-diante-do-home-office-e-do-trabalho-externo-19-12-2016-06-04-acs. Acesso em 29 de abr. 2018.

CASSAR, Vólia Bomfim. BORGES, Leonardo Dias. Comentários à reforma trabalhista. - Rio de Janeiro: Forense; São Paulo: Método. 2017.

DELGADO, Mauricio Godinho. DELGADO, Gabriela Neves. A reforma trabalhista no Brasil: com os comentários à Lei n. 13.467/2017. São Paulo: LTr, 2017.

GARCIA, Gustavo Filipe Barbosa. Curso de direito do trabalho.11ª ed., rev., atual. e ampl. Rio de Janeiro: Forense, 2017. 


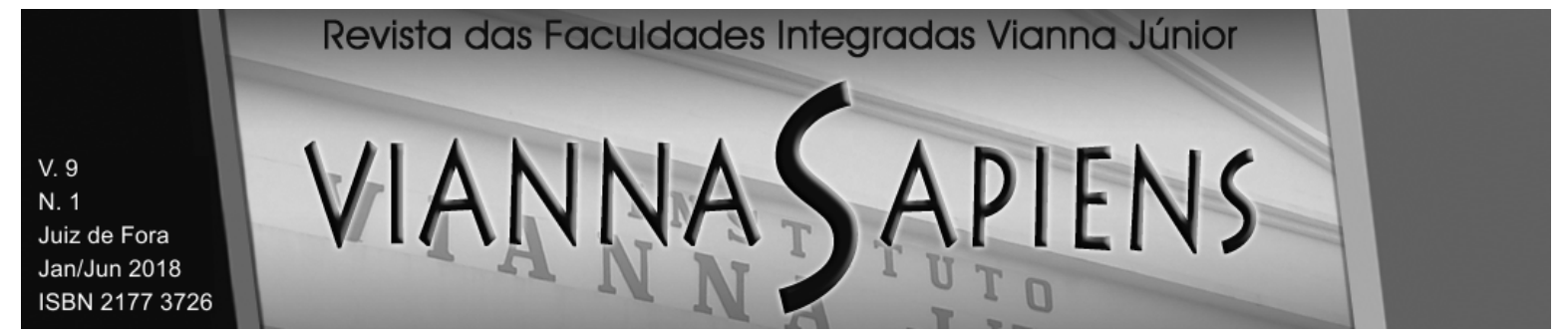

GARCIA, Gustavo Filipe Barbosa. Teletrabalho carece de legislação para garantir o direito à desconexão. Disponível: https://www.conjur.com.br/2016-jun-15/gustavogarcia-teletrabalho-direito-desconexao. Acesso em 29 de abr. 2018.

LEITE. Carlos Henrique Bezerra. Curso de direito do trabalho. 9. Ed. - São Paulo: Saraiva Educação, 2018.

MARTINEZ, Luciano. Curso de direito do trabalho. 8. ed. São Paulo: Saraiva, 2018. p. 396.

MELO. G. M. O teletrabalho na nova CLT. Disponível:

$<$ http://www.migalhas.com.br/dePeso/16,MI263029,71043-

O+teletrabalho+na+nova+CLT>. Acesso em 20 de abr. 2018.

NASCIMENTO, Amauri Mascaro. Curso de direito do trabalho. 20. Ed. São Paulo: Saraiva, 2005.

PAULA. H. M. F de. Teletrabalho: desafios frente a uma novo realidade. In: MIESSA, E.; CORREIA, H. A reforma trabalhista e seus impactos. Salvador: Jus PODIVM, 2017.

RODRIGUES, Bruno Alves. conexão telemática e desconexão valorativa no trabalho - uma crítica à reificação do teletrabalho operada pelo lei n. 13.467/2017, na perspectiva da dialética materialista de karl marx. Revista do Tribunal Regional do

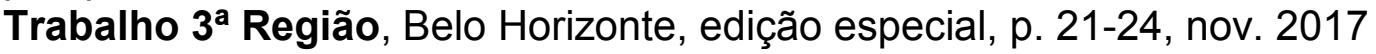

Recebido em 01/05/2018

Publicado em 13/08/2018 